\title{
Association Between Routine Blood Biomarkers and Clinical Phenotypes and Exacerbations in Chronic Obstructive Pulmonary Disease
}

This article was published in the following Dove Press journal: International Journal of Chronic Obstructive Pulmonary Disease

\author{
Alexa Nuñez $\mathbb{D}^{1,2, *}$ \\ Viviana Marras iD ${ }^{3, *}$ \\ Matevz Harlander (iD ${ }^{4}$ \\ Evgeni Mekov ${ }^{5}$ \\ Cristina Esquinas' \\ Matjaz Turel (iD ${ }^{4}$ \\ David Lestan ${ }^{4}$ \\ Rosen Petkov ${ }^{5}$ \\ Nikolay Yanev iD ${ }^{5}$ \\ Pietro Pirina (iD) ${ }^{3}$ \\ Silvia Negri ${ }^{3}$ \\ Marc Miravitlles (ID) 1,2,6 \\ Miriam Barrecheguren ' \\ 'Pneumology Department, Hospital \\ Universitari Vall d'Hebron/Vall d'Hebron \\ Institut de Recerca (VHIR), Barcelona, \\ Spain; ${ }^{2}$ Medicine Department, \\ Autonomous University of Barcelona \\ (UAB), Barcelona, Spain; ${ }^{3}$ Respiratory \\ Unit, AOU Sassari, Sassari, Italy; \\ ${ }^{4}$ Department of Pulmonary Diseases, \\ University Medical Centre Ljubljana, \\ Ljubljana, Slovenia; ${ }^{5}$ Department of \\ Pulmonary Diseases, Medical Faculty, \\ Medical University of Sofia, Sofia, \\ Bulgaria; ${ }^{6} \mathrm{CIBER}$ de Enfermedades \\ Respiratorias (CIBERES), Barcelona, \\ Spain
}

*These authors contributed equally to this work

Correspondence: Marc Miravitlles Pneumology Department, Hospital Universitari Vall d'Hebron, P. Vall d'Hebron I19-129, Barcelona 08035, Spain

Tel +34934893000

Fax +34932748208

Email marcm@separ.es
Introduction: Chronic obstructive pulmonary disease (COPD) is associated with increased lung and systemic inflammation. We aimed to identify associations between easy-to-obtain blood biomarkers and the frequency and severity of exacerbations.

Methods: Cross-sectional, multicentre study performed in four centres in Spain, Italy, Bulgaria, and Slovenia. Blood samples were obtained for blood cell count, C-reactive protein (CRP), alpha-1 antitrypsin (AAT) and fibrinogen analysis. The neutrophil/lymphocyte ratio (NLR), platelet/lymphocyte ratio (PLR) and eosinophil/basophil ratio (EBR) were calculated. Firstly, patients were divided into clinical phenotypes according to the Spanish guidelines of COPD, and secondly, patients were classified into 2 groups: non-exacerbators ( $\leq 1$ ambulatory exacerbation in the previous year) and exacerbators ( $\geq 2$ ambulatory exacerbations or 1 hospitalisation in the previous year). A multivariate stepwise logistic regression model was performed to identify laboratory parameters associated with exacerbators.

Results: A total of 355 patients with a mean age 66 years $(\mathrm{SD}=8.9)$ were included, and $64 \%$ were male. The mean FEV1\% (forced expiratory volume in the first second) was 55\% $(\mathrm{SD}=20 \%$ ), and the mean COPD Assessment Test (CAT) score was 15.6 ( $\mathrm{SD}=7.9)$. One hundred ninety-six $(55.2 \%)$ patients were classified in the non-exacerbator group, and 159 $(44.8 \%)$ were exacerbators. Patients in the exacerbators group presented lower haemoglobin levels $(p=0.019)$ and ERB $(p=0.023)$ but higher CRP levels $(p=0.001)$. In the multivariate analysis, females, higher levels of CRP, lower FEV1\% and low EBR were independently related to exacerbators.

Conclusion: Female sex, having a more severe impairment of lung function, higher CRP levels and a lower EBR are associated with an exacerbator phenotype in COPD.

Keywords: COPD, blood cells, biomarkers, exacerbation, phenotypes

\section{Introduction}

Chronic obstructive pulmonary disease (COPD) is characterised by chronic airflow limitation and persistent symptoms. ${ }^{1}$ COPD is mainly caused by tobacco smoking and is currently the third leading cause of death worldwide. ${ }^{1,2}$

Chronic airway and lung inflammation are the main characteristics of the pathogenesis of COPD and are associated with a collapse of small airways, parenchymal destruction and goblet cell proliferation in bronchial epithelium. ${ }^{3}$ Moreover, it is known that COPD may be associated with systemic inflammation and comorbidities. ${ }^{4}$

The natural course of COPD is altered by episodes of exacerbations characterised by an increase of both pulmonary and systemic inflammation. ${ }^{5}$ In the last years, there 
has been increasing interest in describing biomarkers that could help predict the occurrence of exacerbations of COPD (ECOPD) and the clinical evolution of COPD, and therefore, the use of these biomarkers could help in therapeutic decision making. ${ }^{6}$

Some of the biomarkers proposed in stable and exacerbated COPD patients include neutrophil counts, C-reactive protein (CRP), tumor necrosis factor $\alpha$, interleukin (IL) 6 , IL-8 and fibrinogen. ${ }^{7,8}$ However, only fibrinogen has been accepted as a reliable biomarker for use in clinical trials because of its repeatability and correlation with variables of COPD severity and prognosis, although it is not a good predictor of the risk of ECOPD. ${ }^{9}$

Recent studies have proposed the use of other markers obtained in routine blood analysis, such as the neutrophil/ lymphocyte ratio (NLR), the platelet/lymphocyte ratio (PLR) and the eosinophil/basophil ratio (EBR), as markers of the risk and severity of ECOPD and as prognostic markers of hospital mortality due to ECOPD. ${ }^{10-12}$

The importance of the identification of routine blood test biomarkers lays in better characterisation of COPD patients and personalisation of the management of the disease. The aim of our study was to identify the possible associations between routine blood biomarkers and the frequency and severity of ECOPD in an international cohort of patients with COPD.

\section{Methods}

This was an observational, cross-sectional, multicentre study performed in pneumology departments of four teaching hospitals in Spain, Italy, Slovenia and Bulgaria. We included ambulatory COPD patients of 40 years of age or older; current or former smokers with a smoking history of at least 10 pack-years and a post-bronchodilator $\mathrm{FEV}_{1}$ (forced expiratory volume in the first second)/FVC (forced vital capacity) ratio $<0.7$; and in stable state, at least 1 month following recovery from the last ECOPD. The exclusion criteria were the presence of another chronic respiratory disease (eg cystic fibrosis, severe bronchiectasis, cancer or restrictive lung disease) or systemic inflammatory disease and inability to complete the quality of life questionnaires. Patients were included consecutively if inclusion and exclusion criteria were fulfilled.

\section{Variables}

Sociodemographic characteristics and clinical COPD data were collected from all the patients. Other variables were studied including spirometry, self-reported clinical symptoms (cough, expectoration, wheezing), and number of ECOPD in the previous 12 months collected from the clinical history, and the degree of dyspnoea assessed according to the modified Medical Research Council (mMRC) dyspnoea scale. ${ }^{13}$ The BODEx index ${ }^{14}$ (body mass index, airway obstruction, dyspnoea, severe exacerbations) was calculated,and the COPD Assessment Test $(\mathrm{CAT})^{15}$ score was obtained.

Moderate ECOPD was defined as an acute increase in respiratory symptoms requiring ambulatory treatment with antibiotics and/or systemic corticosteroids. When the episode required treatment in a hospital setting or assistance in the emergency room for at least 24 hrs it was considered severe. ${ }^{6}$

Firstly patients were divided into clinical phenotypes according to the GesEPOC criteria: ${ }^{16}$ 1) non-exacerbator (NE): patients with 0 or 1 ECOPD in the previous year; 2) exacerbator with emphysema (EE): patients presenting at least two ECOPD in the previous year and clinical/radiological or functional evidence of emphysema; 3) exacerbator with chronic bronchitis (ECB): exacerbators with cough and expectoration for at least 3 months of the year over two consecutive years; and 4) asthma-COPD overlap: patients with a concomitant diagnosis of asthma and/ or blood eosinophilia $\geq 300$ cells $/ \mu \mathrm{L}^{17}$

Secondly, they were classified into 2 groups: exacerbators, defined as patients with $\geq 2$ ambulatory exacerbations or 1 hospitalisation, or non-exacerbators defined as patients presenting $\leq 1$ ambulatory exacerbation in the previous year. Finally, patients were classified according to the new Global Obstructive Lung Disease (GOLD) 2019 A-D classification. ${ }^{18}$

\section{Analysis of Biomarkers}

Routine blood analyses were performed during stable phase in all the patients. The following biomarkers were analysed: blood cell count, CRP, alpha1-antitrypsin (AAT) and fibrinogen. In addition, the following indices were calculated: the NLR was defined as the absolute neutrophil count divided by the absolute lymphocyte count, the EBR as the division between the absolute eosinophil count and the absolute basophil count, and finally, the PLR was defined as the platelet count divided by the absolute lymphocyte count.

\section{Statistical Analysis}

Qualitative variables were described with absolute frequencies and percentages. The description of quantitative variables was performed using the mean, standard 
deviation (SD), median and quartiles. The KolmogorovSmirnov test was used to assess the normality of distributions.

The patient characteristics were compared according to the country, phenotype, the presence of previous ECOPD and GOLD A to D groups. In the case of quantitative variables, the Student's $t$-test (Mann-Whitney $U$-test if normality was not assumed) or ANOVA tests (in the case of country and phenotype) were carried out. The Chisquared test (Fisher test for frequencies $<5$ ) was used for the comparison of categorical variables.

A multivariate model was developed using backward stepwise logistic regression analysis including the presence of exacerbator phenotype as the dependent variable. Variables with a significance $<0.2$ in the univariate analysis were included as independent variables. The results were described with odds ratios (OR), 95\% confidence interval (CI) and p-values. For all the tests, p-values $<0.05$ were considered statistically significant. The statistical package SPSS (V 25) was used for the statistical analyses.

\section{Results}

A total of 355 patients were included. The mean age (SD) was 66 years (8.9) and 64.5\% were male. Thirty-three percent were active smokers with a mean tobacco consumption of 40.8 (25.9) pack-years. The mean degree of dyspnoea (mMRC) was $1.8(1)$, and the mean post-bronchodilator FEV1\% was 55\% (19.9\%). Patients had a mean CAT score of 15.6 (7.9) and a mean BODEx index of 2.7 (2). Regarding clinical phenotypes, 181 (51\%) patients were classified as $\mathrm{NE}, 73(20.6 \%)$ as EE, $55(15.5 \%)$ as ECB and $46(13 \%)$ as ACO. The mean rates of moderate and severe exacerbations in the previous year were $0.8(1.2)$ and $0.5(0.9)$ respectively. The sociodemographic and clinical characteristics of the patients are shown in Table 1.

\section{Characteristics of Patients According to the Geographical Region}

No significant differences were found in terms of age, number of active smokers, BMI or CAT scores (Table 1). However, compared with patients from other countries, COPD patients in Spain had greater tobacco exposure $(\mathrm{p}<0.001)$, more severely impaired lung function in terms of FEV1\% $(\mathrm{p}<0.001)$, a higher BODEx index and a higher rate of moderate ECOPD. A higher BODEx index was also observed in Bulgarian patients and more frequent moderate ECOPD in Italian patients. On the other hand,
COPD patients in Bulgaria had a higher rate of severe ECOPD $(p<0.001)$ and higher CRP levels $(p<0.001)$ than patients from other countries (Table 1).

\section{Characteristics of Patients According to Clinical Phenotypes}

No significant differences were observed between clinical phenotypes in terms of age, sex or smoking history. However, COPD patients classified as ECB had a higher BMI $(\mathrm{p}<0.001)$ and more frequent moderate ECOPD in the previous year than the remaining patients $(\mathrm{p}<0.001)$. Regarding blood biomarkers, ECB patients presented higher CRP levels $(\mathrm{p}<0.001)$ and NLR $(\mathrm{p}=0.024)$ but had a lower platelet count ( $\mathrm{p}=0.018)$.

COPD patients classified as EE had a higher degree of dyspnoea $(p<0.001)$, higher BODEx $(p<0.001)$ and CAT scores $(p<0.001)$, a higher rate of ECOPD in the previous year $(\mathrm{p}<0.001)$ and more severe lung function impairment $(\mathrm{p}<0.001)$ than the remaining clinical phenotypes.

ACO patients presented a lower degree of dyspnoea and better FEV1\% $(\mathrm{p}<0.001)$ as well as a higher eosinophil count $(\mathrm{p}<0.001), \operatorname{ELR}(\mathrm{p}=0.001)$ and $\operatorname{EBR}(\mathrm{p}<0.001)$ (Table 2).

\section{Routine Blood Biomarkers According to the Presence of Exacerbations and GOLD Groups}

Out of 355 COPD patients, 196 (55.2\%) were classified in the non-exacerbator group and $159(44.8 \%)$ were classified as exacerbators. On comparing blood parameters between the two groups, we found that the exacerbators group presented lower haemoglobin levels $(\mathrm{p}=0.019)$ and EBR $(\mathrm{p}=0.023)$. In contrast, they presented higher CRP levels $(p=0.001)$. Figures 1 and 2 show the CRP levels and the EBR according to exacerbations, respectively. As for the rest of the biomarkers studied, we did not find significant differences between groups. When comparing between the GOLD groups, $\mathrm{C}$ and $\mathrm{D}$ patients presented higher levels of CRP $(\mathrm{p}<0.05)$, and lower levels of AAT were observed in the group $\mathrm{C}(\mathrm{p}<0.05)$. No other significant differences were found in the rest of the studied biomarkers. Complete data are described in Table 3.

\section{Multivariate Analysis to Determine Factors Associated with Exacerbations}

Multivariate analysis showed that females $(\mathrm{OR}=5$, $\mathrm{p}=0.002)$, high levels of CRP $(\mathrm{OR}=1.35, \mathrm{p}=0.049)$, 
Table I Sociodemographic and Clinical Characteristics of COPD Patients Included

\begin{tabular}{|c|c|c|c|c|c|c|}
\hline Variable & Global $(\mathbf{N}=355)$ & Spain $(\mathbf{N}=\mathbf{8 0})$ & Italy $(\mathbf{N}=\mathbf{8 2})$ & Slovenia $(\mathbf{N}=97)$ & Bulgaria $(\mathrm{N}=96)$ & *p value \\
\hline Age, years & $66.6(8.9)$ & $65.9(8.9)$ & $68.5(10.3)$ & 67.1 (8.1) & $65.1(8.1)$ & 0.065 \\
\hline Sex, male (\%) & $229(64.5)$ & $57(71.3)$ & $59(72)$ & $53(54.6)$ & $60(62.5)$ & 0.049 \\
\hline Ex-smokers (\%) & $233(66.8)$ & $60(75)$ & $51(67.1)$ & $61(62.9)$ & $61(63.5)$ & 0.314 \\
\hline Pack-years (smokers/ex) & $4 I(26)$ & $52(32)$ & $46(28)$ & $39(22)$ & $28(15)$ & $<0.001$ \\
\hline BMI $\left(\mathrm{kg} / \mathrm{m}^{2}\right)$ & $25.8(5)$ & $25.1(5.4)$ & $26.1(5.6)$ & $25.6(4.6)$ & $26.3(4.5)$ & 0.421 \\
\hline $\mathrm{mMRC}$ & $1.8(1)$ & $1.8(0.9)$ & $2(1)$ & $\mathrm{I} .4(\mathrm{I})$ & $2.1(I)$ & $<0.001$ \\
\hline Cough (\%) & $240(67.6)$ & $45(56.3)$ & $50(61)$ & $55(56.7)$ & $90(93.8)$ & $<0.001$ \\
\hline Wheezing (\%) & $140(39.4)$ & $24(30)$ & $26(31.7)$ & $21(21.6)$ & 69 (71.9) & $<0.001$ \\
\hline Sputum (\%) & $228(64.4)$ & $45(56.3)$ & $54(65.9)$ & $61(62.9)$ & $68(71.6)$ & 0.201 \\
\hline Dyspnoea (\%) & $295(83.1)$ & $64(80)$ & $70(85.4)$ & $82(84.5)$ & $79(82.3)$ & 0.793 \\
\hline $\mathrm{FVC}(\mathrm{mL})$ & $2708(956)$ & $2395(922)$ & $238 I(715)$ & $3060(962)$ & $2752(1043)$ & $<0.001$ \\
\hline FVC (\%) & $67.9(18.3)$ & $65.7(18.4)$ & $76.8(16.6)$ & $82.2(19.3)$ & $66.4(18.9)$ & $<0.001$ \\
\hline FEVI (mL) & $1475(625)$ & $1253(58 \mid)$ & $1518(489)$ & 1567 (697) & 1525 (649) & 0.005 \\
\hline FEVI (\%) & $55(19.9)$ & $44.6(16.4)$ & $62.8(16.1)$ & $56.2(21.6)$ & $55.8(20.2)$ & $<0.001$ \\
\hline FEVI/FVC & $54.2(12.1)$ & $51.7(10.2)$ & $60.5(10.2)$ & $50.1(13.1)$ & $55.7(11.7)$ & 0.412 \\
\hline \multicolumn{7}{|l|}{ Phenotypes(\%) } \\
\hline$-N E$ & $|8|(5 \mid)$ & $36(45)$ & $57(69.5)$ & $66(68)$ & $22(22.9)$ & $<0.001$ \\
\hline$-A C O$ & $46(13)$ & $8(10)$ & $7(8.5)$ & $18(18.6)$ & $13(13.5)$ & \\
\hline$-\mathrm{EE}$ & $73(20.6)$ & $30(37.5)$ & $6(7.3)$ & $7(7.2)$ & $30(31.3)$ & \\
\hline$-E C B$ & $55(15.5)$ & $6(7.5)$ & $12(14.6)$ & $6(6.2)$ & $31(32.3)$ & \\
\hline BODEx index & $2.7(2)$ & $3.3(1.9)$ & $2.1(1.5)$ & $1.9(1.8)$ & $3.3(2.1)$ & $<0.001$ \\
\hline CAT & I5.6 (7.9) & $15(7.9)$ & $17(7.4)$ & $14.9(6.6)$ & $15.6(9.2)$ & 0.294 \\
\hline Moderate exacerbations & $0.8(1.2)$ & $\mathrm{I}(\mathrm{I} .3)$ & $1.2(1.5)$ & $0.5(0.9)$ & $0.7(0.8)$ & $<0.001$ \\
\hline Severe exacerbations & $0.5(0.9)$ & $0.7(\mathrm{I})$ & $0.2(0.5)$ & $0.1(0.4)$ & I.I (0.9) & $<0.001$ \\
\hline Leukocytes $\left(\times 10^{3} \mu \mathrm{L}\right)$ & $8.4(2.2)$ & $8.5(2.4)$ & $8.1(1.8)$ & $8.2(2.1)$ & $8.6(2.3)$ & 0.342 \\
\hline Eosinophils $\left(\times 10^{3} \mu \mathrm{L}\right)$ & $0.2(0.4)$ & $0.3(0.6)$ & $0.3(0.3)$ & $0.2(0.1)$ & $0.2(0.2)$ & 0.196 \\
\hline CRP $(\mathrm{mg} / \mathrm{dL})$ & $2.4(3.3)$ & $0.9(1.2)$ & $0.8(\mathrm{I} . \mathrm{I})$ & I.5 (I.4) & $4.4(4.2)$ & $<0.001$ \\
\hline AAT (mg/dL) & $|5|(34)$ & $|5|(37)$ & $150(48)$ & $159(28)$ & $143(25)$ & 0.013 \\
\hline Fibrinogen $(\mathrm{mg} / \mathrm{dL})$ & $4.6(13.2)$ & $7.2(2.7)$ & $3.3(0.9)$ & $3.9(0.8)$ & $4(1)$ & 0.269 \\
\hline
\end{tabular}

Notes: Values are means (standard deviations), unless otherwise specified. *p value results when comparing data from the four countries by ANOVA or Chi-squared tests, considered statistically significant when $<0.05$.

Abbreviations: BMI, body mass index; mMRC, modified Medical Research Council; FVC, forced vital capacity; FEVI, forced expiratory volume in the first second; NE, nonexacerbator; ACO, asthma-COPD overlap; EE, exacerbator with emphysema; ECB, exacerbator with chronic bronchitis; BODEx, body mass index; airway obstruction; dyspnoea; severe exacerbations; CAT, COPD assessment test; CRP, C-reactive protein; AAT, alphal-antitrypsin.

a lower FEV1\% (OR=0.92, $\mathrm{p}=0.008)$ and a low $\mathrm{EBR}$ $(\mathrm{OR}=0.489, \mathrm{p}=0.002)$ were significantly and independently related to being an exacerbator (Table 4).

\section{Discussion}

COPD is a chronic respiratory disease that is associated with systemic inflammation, ${ }^{4}$ and increased systemic inflammation may be associated with a higher risk of exacerbations and more or more severe comorbidities. ${ }^{4}$ Exacerbations play an important role in the natural history of COPD, being one of the main causes of mortality. ${ }^{19}$ Nowadays, the best predictor of ECOPD is having a history of previous ECOPD, ${ }^{20,21}$ and there are still no validated biomarkers to help recognize the frequent exacerbator phenotype of COPD. The identification of easy-to-obtain systemic biomarkers associated with frequent exacerbations may help physicians to identify at risk COPD patients and take adequate preventive measures. In this context, we analysed data from this multicentre and international study in order to identify the possible associations of different routine blood test biomarkers with the history of ECOPD and clinical phenotypes.

In our cohort, patients with exacerbations presented lower levels of haemoglobin and EBR and higher levels of CRP. Moreover, in the multivariate analysis, females, 
Table 2 Characteristics of the Patients According to the Clinical Phenotype

\begin{tabular}{|c|c|c|c|c|c|}
\hline Variables & $\begin{array}{l}\text { Non- } \\
\text { Exacerbator } \\
(\mathrm{N}=18 \mathrm{I})\end{array}$ & $A C O(N=46)$ & $\begin{array}{l}\text { Exacerbator with } \\
\text { Emphysema }(\mathrm{N}=73)\end{array}$ & $\begin{array}{l}\text { Exacerbator with } \\
\text { Chronic Bronchitis } \\
(\mathrm{N}=55)\end{array}$ & *p value \\
\hline Age, years & $67.1(8.3)$ & $65.5(9.4)$ & $66.6(8.2)$ & $65.9(11)$ & 0.650 \\
\hline Sex, male (\%) & $122(67.4)$ & $24(52.2)$ & $47(64.4)$ & $36(65.5)$ & 0.291 \\
\hline Ex smokers (\%) & $112(63.3)$ & $34(73.9)$ & $56(79.7)$ & $31(58.5)$ & 0.074 \\
\hline Pack-years (smokers and ex) & $44(27)$ & 31 (22) & $4 \mathrm{I}(23)$ & $37(27)$ & 0.010 \\
\hline BMI $\left(\mathrm{kg} / \mathrm{m}^{2}\right)$ & $25.5(4.9)$ & $26.2(4.8)$ & $24.2(4.2)$ & $28.4(5.8)$ & $<0.001$ \\
\hline $\mathrm{mMRC}$ & $1.6(0.9)$ & $1.5(0.9)$ & $2.3(0.9)$ & $2.1(1)$ & $<0.001$ \\
\hline FEVI (\%) & $57.8(18.4)$ & $64.6(16.1)$ & $39.3(16.6)$ & $58.7(20.5)$ & $<0.001$ \\
\hline BODEx index & $2(1.6)$ & $1.9(1.5)$ & $4.6(1.8)$ & $3.1(1.7)$ & $<0.001$ \\
\hline CAT & I4.I (7.1) & I4.7 (7.5) & I8.4 (8.8) & $17.4(7.9)$ & $<0.001$ \\
\hline Moderate exacerbations & $0.4(0.5)$ & $0.8(1.2)$ & $\mathrm{I} .5(\mathrm{I} .3)$ & $1.5(1.6)$ & $<0.001$ \\
\hline Severe exacerbations & $0.1(0.2)$ & $0.6(1)$ & $1.3(1)$ & $\mathrm{I}(0.8)$ & $<0.001$ \\
\hline \multicolumn{6}{|l|}{ Laboratory Findings } \\
\hline Haemoglobin (g/dL) & I4.5 (I.6) & I4.5 (I.2) & $14.2(1.8)$ & I4.2 (I.7) & 0.511 \\
\hline Haematocrit (\%) & $44.2(4.4)$ & $43.8(4.1)$ & $44.3(5.3)$ & $44.3(5.6)$ & 0.937 \\
\hline Platelets $\left(\times 10^{3} \mu \mathrm{L}\right)$ & $252(78)$ & $266(62)$ & $262(70)$ & $246(64)$ & 0.018 \\
\hline Fibrinogen (mg/dL) & $5.3(18.9)$ & $3.7(0.8)$ & $4(1)$ & $4(0.8)$ & 0.269 \\
\hline CRP (mg/dL) & $1.6(2.3)$ & I.4 (I.4) & $3.1(3.8)$ & $3.8(4.5)$ & $<0.001$ \\
\hline AAT (mg/dL) & $154(35)$ & $|4|$ (27) & $148(37)$ & $154(31)$ & 0.013 \\
\hline Leukocyte $\left(\times 10^{3} \mu \mathrm{L}\right)$ & $8.3(2.3)$ & $8.2(1.8)$ & $8.5(2.3)$ & $8.5(2)$ & 0.759 \\
\hline Neutrophil $\left(\times 10^{3} \mu \mathrm{L}\right)$ & $5.5(4.1)$ & $6.2(8.5)$ & $5.5(1.9)$ & $5.4(1.9)$ & 0.803 \\
\hline Neutrophil (\%) & $62.2(9.5)$ & $59.6(10.8)$ & $64(9.7)$ & $62.5(10.4)$ & 0.136 \\
\hline Lymphocytes $\left(\times 10^{3} \mu \mathrm{L}\right)$ & $2.4(2.9)$ & $2.8(3.8)$ & $2.1(0.8)$ & $2.1(0.7)$ & 0.506 \\
\hline Lymphocytes (\%) & $26.6(8.4)$ & $27.8(9.4)$ & $24.6(8)$ & $26.1(9)$ & 0.220 \\
\hline Eosinophils $\left(\times 10^{3} \mu \mathrm{L}\right)$ & $0.2(0.2)$ & $0.5(0.8)$ & $0.2(0.2)$ & $0.2(0.2)$ & $<0.001$ \\
\hline Eosinophils (\%) & $2.4(1.7)$ & $3.8(3)$ & $2.3(1.9)$ & $2.5(2)$ & $<0.001$ \\
\hline NLR & $2.8(1.6)$ & $2.7(2)$ & $3.1(1.7)$ & $3.4(3.9)$ & 0.024 \\
\hline ELR & $0.1(0.1)$ & $0.2(0.4)$ & $0.1(0.1)$ & $0.1(0.1)$ & 0.001 \\
\hline EBR & $4.2(3.3)$ & $8(10)$ & $3.4(3.1)$ & $3(3)$ & $<0.001$ \\
\hline PLR & I33 (7I) & $138(87)$ & I44 (59) & $132(76)$ & 0.708 \\
\hline Platelets $\left(\times 10^{3} \mu \mathrm{L}\right)$ & $252(72)$ & $266(62)$ & $262(70)$ & $246(64)$ & 0.459 \\
\hline
\end{tabular}

Notes: Values are means (standard deviations), unless otherwise specified. *p value results when comparing data between all the clinical phenotypes by ANOVA or Chisquared tests, considered statistically significant when $<0.05$.

Abbreviations: BMI, body mass index; mMRC, modified Medical Research Council; FVC, forced vital capacity; FEVI, forced expiratory volume in the first second; NE, nonexacerbator; ACO, asthma-COPD overlap; EE, exacerbator with emphysema; ECB, exacerbator with chronic bronchitis; BODEx, body mass index; airway obstruction; dyspnoea; exacerbations; CAT, COPD assessment test; CRP, C-reactive protein; AAT, alphal-antitrypsin; NLR, neutrophil/lymphocyte ratio; ELR, eosinophil/lymphocyte ratio; EBR, eosinophil/basophil ratio; PLR, platelet/lymphocyte ratio.

a more impaired FEV1\%, higher levels of CRP and a lower EBR were variables independently and significantly associated with exacerbations.

Low haemoglobin concentrations are commonly observed in COPD patients and have been studied as a prognostic factor in this disease. ${ }^{22,23}$ As an example, several studies have observed that presenting low haemoglobin concentrations during admission due to ECOPD is related to increased mortality after discharge. ${ }^{24-26}$ In the present study, patients reporting at least two ECOPD or one hospitalisation in the previous year had significantly lower haemoglobin concentrations, although haemoglobin was not identified as an associated independent factor in the multivariate analysis.

Regarding inflammatory blood biomarkers, we found higher CRP concentrations in patients with more exacerbations, especially in those with chronic bronchitis. CRP is the prototypical acute-phase reactant and is a useful biomarker to detect infection and tissue injury. CRP has been used to control the progression of chronic diseases such as inflammatory rheumatoid diseases and as a biomarker of future cardiovascular events. ${ }^{27}$ In COPD, previous studies have described elevated CRP levels as a good predictor for readmission and a marker of poor outcome after an 


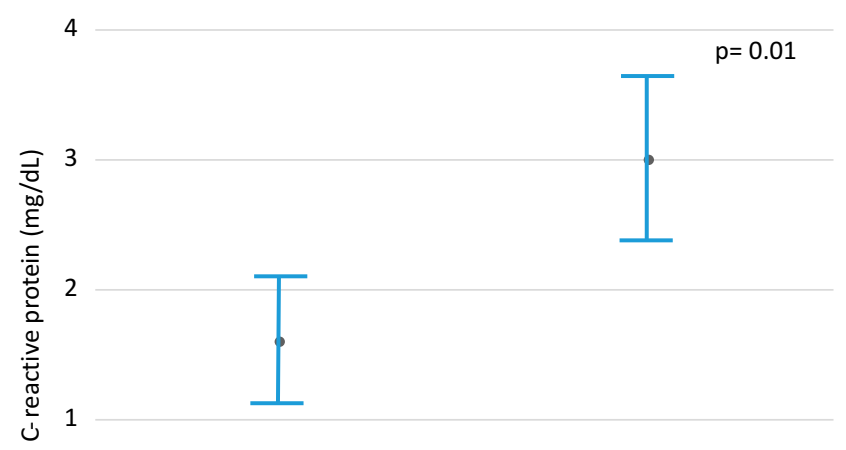

0

Non-exacerbators

Exacerbators

Figure I C- reactive protein (CRP) in exacerbators and non-exacerbators. Notes: Non-exacerbators: patients with $\leq 1$ ambulatory exacerbation in the previous year; Exacerbators: patients with $\geq 2$ ambulatory exacerbations or I hospitalisation in the previous year.

Abbreviation: CRP, C-reactive protein.

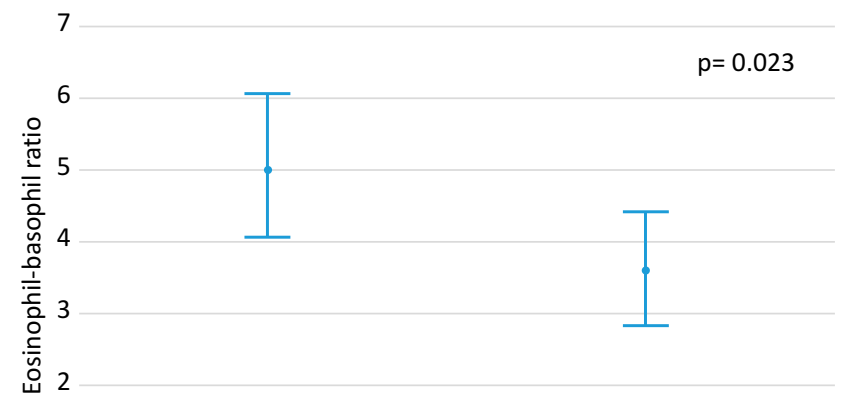

1

0 Non-exacerbators

Exacerbators

Figure 2 Eosinophil/basophil ratio (EBR) in exacerbators and non-exacerbators. Notes: Non-exacerbators: patients with $\leq 1$ ambulatory exacerbation in the previous year; Exacerbators: patients with $\geq 2$ ambulatory exacerbations or 1 hospitalisation in the previous year.

ECOPD. ${ }^{28,29}$ Elevated baseline CRP levels have also been associated with higher mortality, ${ }^{30}$ and together with a high fibrinogen and leukocyte count were also associated with increased risk of having exacerbations. ${ }^{31}$

In addition, AAT levels were lower in ACO and EE. Higher AAT and CRP levels have shown to be associated with an increased risk of COPD in the general population without AAT deficiency; ${ }^{32,33}$ however, the reduced levels of AAT observed in ACO patients have not been described previously. $^{34,35}$

Eosinophils are end-stage cells produced under the influence of macrophage colony-stimulating factor, interleukin (IL)-3 and the late differentiation factor IL-5. ${ }^{36}$ Non eosinophilic exacerbations in COPD are related to more severe infections and a higher hospital stay. ${ }^{37}$ On the other hand, basophils are related to inflammatory responses in immune diseases. ${ }^{38}$ The use of EBR as a biomarker in COPD was previously described by Xiong et al, ${ }^{12}$ who demonstrated that a higher EBR was associated with a lower rate of exacerbations and better survival. In accordance these results, a lower EBR was observed in our patients with frequent exacerbations. As expected, the highest EBR was observed in patients with ACO, who also had higher eosinophil levels, suggesting that increased eosinophilic inflammation in COPD is a marker of better prognosis compared with other phenotypes of the disease. ${ }^{11,34}$

In contrast to previous data, we could not replicate the relationship found between some other biomarkers and exacerbations. In our study, neither the NLR nor the PLR or platelet count, were significantly elevated in patients with a history of exacerbations. However, the NLR was significantly elevated if the exacerbators had the chronic bronchitis phenotype. In contrast, exacerbators with emphysema showed a higher but non-significant PLR.

Elevated NLRs have been associated with the risk of exacerbations in previous studies, although no differences between different types of exacerbators (i.e chronic bronchitic, emphysematous or ACO) were reported. ${ }^{39,40}$ An elevated platelet count has been described to be associated with worse COPD morbidity, more severe lung function impairment, a higher likelihood of presenting ECOPD $^{41}$ and with increased mortality during an exacerbation. ${ }^{42}$ Similarly, an elevated PLR has been proposed as a useful marker for increased risk of exacerbations and mortality after discharge for an ECOPD. ${ }^{43-45}$

Some of the differences observed in the associations between biomarkers and exacerbations between our study and previous studies may be related to the inclusion criteria. Most of the previous studies included patients during an ambulatory or hospital ECOPD, and therefore, significantly increased inflammatory biomarkers would be expected. In our study, the patients were included during a stable state and associations between the serum concentrations of biomarkers with a previous history of ECOPD were analysed. Although this interference was eliminated from our study by including only stable patients, it cannot be ruled out that patients with frequent exacerbations and chronic bronchitis may have chronic colonization and this might explain some elevated biomarkers, such as CRP.

The main limitation of our study was the crosssectional design that did not allow analysis of the prognostic value of the biomarkers, but rather, only the 
Table 3 Blood Biomarkers According to Non-Exacerbator/Exacerbator Phenotype and GOLD Groups

\begin{tabular}{|c|c|c|c|c|c|c|}
\hline \multirow[t]{2}{*}{ Laboratory parameters } & \multirow{2}{*}{$\begin{array}{l}\text { Non- Exacerbators } \\
(\mathrm{N}=196)\end{array}$} & \multirow{2}{*}{$\begin{array}{l}\text { Exacerbators } \\
(N=159)\end{array}$} & \multicolumn{4}{|c|}{ GOLD Groups } \\
\hline & & & $\begin{array}{l}\text { Group A } \\
(N=45)\end{array}$ & $\begin{array}{l}\text { Group B } \\
(N=\mid 48)\end{array}$ & $\begin{array}{l}\text { Group C } \\
(N=20)\end{array}$ & $\begin{array}{l}\text { Group D } \\
(N=142)\end{array}$ \\
\hline Haemoglobin $(\mathrm{g} / \mathrm{dL})$ & $14.5(1.5)$ & $14.2(1.6)^{\mathrm{a}}$ & $14.6(1.5)$ & I4.5 (I.6) & I4.8 (I.3) & |4.| (I.7) \\
\hline Haematocrit (\%) & $44(4.6)$ & $44.2(4.9)$ & $44.5(4.4)$ & $44.1(4.5)$ & $46.2(3.8)$ & $43.8(5.2)$ \\
\hline Platelets $\left(\times 10^{3} \mu \mathrm{L}\right)$ & $25 \mid(77)$ & $260(66)$ & $261.6(75)$ & $249.3(79)$ & $245.3(61)$ & $261.5(67)$ \\
\hline Fibrinogen (mg/dL) & $3.8(0.8)$ & $3.9(0.9)$ & $4(0.9)$ & $5.5(2.8)$ & $3.8(0.9)$ & $3.9(0.9)$ \\
\hline CRP $(\mathrm{mg} / \mathrm{dL})$ & $1.6(2.2)$ & $3.0(3.9)^{\mathrm{b}}$ & $\mathrm{I} .4(\mathrm{I} .6)$ & I.7 (2.5) & $2.8(3.2)$ & $3(3.9)^{\mathrm{c}}$ \\
\hline AAT (mg/dL) & $153(34)$ & 149 (33) & $144.9(34)$ & $155.6(35)$ & $134(34)$ & $152(33)^{c}$ \\
\hline Leukocyte $\left(\times 10^{3} \mu \mathrm{L}\right)$ & $8.3(2.2)$ & $8.4(2.1)$ & $8.2(2)$ & $8.3(2.3)$ & $8.2(2.1)$ & $8.4(2.1)$ \\
\hline Neutrophil $\left(\times 10^{3} \mu \mathrm{L}\right)$ & $5.7(2.7)$ & $5.3(1.8)$ & $5.1(1.7)$ & $6(6.5)$ & $5.1(1.6)$ & $5.4(1.9)$ \\
\hline Lymphocyte $\left(\times 10^{3} \mu \mathrm{L}\right)$ & $2.5(3.3)$ & $2.1(0.7)$ & $2.1(0.6)$ & $2.6(3.9)$ & $2.2(0.8)$ & $2.1(0.7)$ \\
\hline Eosinophils $\left(\times 10^{3} \mu \mathrm{L}\right)$ & $0.2(0.4)$ & $0.2(0.2)$ & $0.2(0.2)$ & $0.3(0.5)$ & $0.2(0.2)$ & $0.2(0.2)$ \\
\hline Eosinophils (\%) & $2.4(1.8)$ & $2.7(2.3)$ & $2.7(1.4)$ & $2.4(1.9)$ & $2.6(2.2)$ & $2.7(2.3)$ \\
\hline Basophil $\left(\times 10^{3} \mu \mathrm{L}\right)$ & $0.5(0.8)$ & $0.5(0.5)$ & $0(0)$ & $0.1(0.1)$ & $0.1(0.1)$ & $0(0)$ \\
\hline NLR & $2.8(1.6)$ & $3.0(2.7)$ & $2.6(1.1)$ & $2.9(1.8)$ & $2.8(1.5)$ & $3.1(2.8)$ \\
\hline ELR & $0.1(0.2)$ & $0.1(0.1)$ & $0.1(0.1)$ & $0.1(0.2)$ & $0.1(0.1)$ & $0.1(0.1)$ \\
\hline EBR & $5.0(6.1)$ & $3.6(3.1)^{\mathrm{a}}$ & $5.6(5.9)$ & $4.9(6.2)$ & $3(2.4)$ & $3.7(3.2)$ \\
\hline PLR & 134 (72) & $|4|$ (72) & 134.1 (62) & $131.9(76)$ & $128.9(53)$ & I42.3 (74) \\
\hline
\end{tabular}

Notes: Values are means (standard deviation), unless otherwise specified; ${ }^{a} \mathrm{P}$ value $<0.05$ when comparing the non-exacerbator and exacerbator groups; ${ }^{\mathrm{b}} \mathrm{P}$ value $<0.0 \mathrm{I}$ when comparing the non-exacerbator and exacerbator groups; ${ }^{c} \mathrm{P}$ value $<0.05$ when comparing the GOLD groups (A, B, C and D).

Abbreviations: CRP, C-reactive protein; AAT, alphal-antirypsin; NLR, neutrophil/lymphocyte ratio; ELR, eosinophil/lymphocyte ratio; EBR, eosinophil/basophil ratio; PLR, platelet/lymphocyte ratio.

Table 4 Univariate and Multivariate Logistic Regression Analyses to Determine Factors Associated with Exacerbations

\begin{tabular}{|c|c|c|c|c|}
\hline \multirow[t]{2}{*}{ Variable } & \multicolumn{2}{|l|}{ Univariate } & \multicolumn{2}{|l|}{ Multivariate } \\
\hline & Odds Ratio (95\% Confidence Interval) & p value & Odds Ratio ( $95 \%$ Confidence Interval) & p value \\
\hline Age & $0.98(0.96-1.01)$ & 0.248 & - & - \\
\hline Sex (female) & $1.33(0.85-2.04)$ & 0.215 & $5(1.17-8.33)$ & 0.002 \\
\hline Pack-years & $0.99(0.98-1.00)$ & 0.041 & - & - \\
\hline $\mathrm{mMRC}$ & $1.70(1.35-2.13)$ & $<0.001$ & - & - \\
\hline CAT score & $1.06(1.03-1.09)$ & $<0.001$ & - & - \\
\hline FEVI\% & $0.97(0.96-0.99)$ & $<0.001$ & $0.92(0.89-0.98)$ & 0.008 \\
\hline \multicolumn{5}{|l|}{ Laboratory parameters: } \\
\hline - White blood cells & $1.03(0.94-1.14)$ & 0.486 & - & - \\
\hline - Haemoglobin & $0.98(0.97-1.00)$ & 0.077 & - & - \\
\hline - Platelets & $1.00(0.99-1.005)$ & 0.274 & - & - \\
\hline - Fibrinogen & $1.19(0.93-1.54)$ & 0.157 & - & - \\
\hline - CRP & $1.18(1.06-1.30)$ & 0.002 & $1.35(1.01-1.83)$ & 0.049 \\
\hline - AAT & $0.99(0.99-1.00)$ & 0.266 & - & - \\
\hline - NLR & $1.06(0.96-1.18)$ & 0.254 & - & - \\
\hline - ELR & $0.86(0.20-3.68)$ & 0.845 & - & - \\
\hline - EBR & $0.92(0.85-0.99)$ & 0.048 & $0.48(0.31-0.76)$ & 0.002 \\
\hline - PLR & $1.00(0.99-1.01)$ & 0.298 & & \\
\hline
\end{tabular}

Abbreviations: mMRC, modified Medical Research Council; CAT, COPD Assessment Test; FEVI, forced expiratory volume in the first second; CRP, C-reactive protein; AAT, alphal-antitrypsin; NLR, neutrophil/lymphocyte ratio; ELR, eosinophil/lymphocyte ratio; EBR, eosinophil/basophil ratio; PLR, platelet/lymphocyte ratio.

associations. Therefore, it would be necessary to evaluate these biomarkers as prognostic factors in a study with a prospective design, including populations with patients with different degrees of disease severity and better characterization in terms of bronchial colonization and CT scan evidence of emphysema or bronchiectasis.

In conclusion, together with female sex and having a lower FEV1, higher CRP levels and a lower EBR were 
associated with a higher rate of exacerbations in COPD. If confirmed in prospective studies, these routine blood biomarkers can be useful for physicians to detect patients at high risk of presenting exacerbations.

\section{Ethics and Consent Statement}

All the procedures in this study were performed in accordance with the ethical standards of the Institutional Review Boards and with the Declaration of Helsinki. The study was approved by the Ethics Committee of the Hospital Vall d'Hebron, Barcelona, Spain (number: PR(AG) 417/2017). Written informed consent was obtained from all the study participants.

\section{Funding}

This research did not receive any specific grant from funding agencies in the public, commercial, or not-forprofit sectors.

\section{Disclosure}

Alexa Nuñez and Viviana Marras are co-first authors in this study. Alexa Nuñez is the recipient of a Rio Hortega contract in the 2019 Strategic Action Health Call from the Instituto de Salud Carlos III for the years 2020-2022. Viviana Marras from the University of Sassari (Italy) was the recipient of an Erasmus Placement for a short stay at the Pneumology Department of University Hospital Valld'Hebron (Barcelona, Spain). Miriam Barrecheguren is the recipient of a Rio Hortega contract in the 2017 Strategic Action Health Call from the Instituto de Salud Carlos III for the years 20182019. Matevz Harlander has received speaker or consulting fees from AstraZeneca, Berlin-Chemie, Menarini, Boehringer Ingelheim, Chiesi, GlaxoSmithKline, Novartis and Teva, all unrelated to this manuscript. Evgeni Mekov has received speaker or consulting fees from Astra Zeneca and Chiesi, all unrelated to this manuscript. Cristina Esquinas has received speaker fees from CSL Behring. Matjaz Turel has received speaker or consulting fees from AstraZeneca, Berlin-Chemie, Menarini, Boehringer Ingelheim, Chiesi, GlaxoSmithKline, Novartis and Teva, all unrelated to this manuscript. David Lestan has received speaker or consulting fees from Boehringer Ingelheim and Roche, all unrelated to this manuscript. Rosen Petkov has received speaker or consulting fees from Astra Zeneca and Boehringer Ingelheim, all unrelated to this manuscript. Nikolay Yanev has received speaker or consulting fees from Astra Zeneca, Boehringer Ingelheim, Berlin Chemie and Chiesi, all unrelated to this manuscript. Pietro Pirina has received speaker fees from Chiesi, Menarini,
Novartis, Mundifarma, Glaxo Smith Kline, all unrelated to this manuscript. Marc Miravitlles has received speaker or consulting fees from AstraZeneca, Bial, Boehringer Ingelheim, Chiesi, Cipla, CSL Behring, Laboratorios Esteve, Ferrer, Gebro Pharma, GlaxoSmithKline, Grifols, Kamada, Menarini, Mereo Biopharma, Novartis, pH Pharma, Rovi, Sanofi, Sandoz, TEVA, Verona Pharma and Zambon, and research grants from GlaxoSmithKline and Grifols, unrelated to this manuscript. Miriam Barrecheguren has received speaker fees from Grifols, Menarini, CSL Behring, GSK and consulting fees from GSK, Novartis and Gebro Pharma. The authors report no other conflicts of interest in this work.

\section{References}

1. Decramer M, Janssens W, Miravitlles M. Chronic obstructive pulmonary disease. Lancet. 2012;379(9823):1341-1351. doi:10.1016/ S0140-6736(11)60968-9

2. GBD 2017 Causes of Death Collaborators. Global, regional, and national age-sex-specific mortality for 282 causes of death in 195 countries and territories, 1980-2017: a systematic analysis for the Global Burden of Disease Study 2017. Lancet. 2018;392(10159):1736-1788.

3. MacNee W. Pathogenesis of chronic obstructive pulmonary disease. Proc Am Thorac Soc. 2005;2(4):258-266. doi:10.1513/pats.200504-045SR

4. Walter RE, Wilk JB, Larson MG, et al. Systemic inflammation and COPD: the Framingham Heart Study. Chest. 2008;133(1):19-25. doi: $10.1378 /$ chest.07-0058

5. Anzueto A, Miravitlles M. Chronic obstructive pulmonary disease exacerbations: a need for action. Am J Med. 2018;131:15-22. doi:10.1016/j.amjmed.2018.05.003

6. Wedzicha JA, Miravitlles M, Hurst JR, et al. Management of COPD exacerbations: an European Respiratory Society/American Thoracic Society (ERS/ATS) guideline. Eur Respir J. 2017;49:1600791. doi:10.1183/13993003.00791-2016

7. Bradford E, Jacobson S, Varasteh J, et al. The value of blood cytokines and chemokines in assessing COPD. Respir Res. 2017;18:180. doi:10.1186/s12931-017-0662-2

8. Faner R, Tal-Singer R, Riley JH, et al. ECLIPSE Study Investigators. Lessons from ECLIPSE: a review of COPD biomarkers. Thorax. 69;2014:666-672. doi:10.1136/thoraxjnl-2013-204778

9. Miller BE, Tal-Singer R, Rennard SI, et al. Plasma fibrinogen qualification as a drug development tool in chronic obstructive pulmonary disease. Perspective of the chronic obstructive pulmonary disease biomarker qualification consortium. Am J Respir Crit Care Med. 2016;193(6):607-613. doi:10.1164/rccm.201509-1722PP

10. Yao C, Liu X, Tang Z. Prognostic role of neutrophil-lymphocyte ratio and platelet-lymphocyte ratio for hospital mortality in patients with AECOPD. Int J Chron Obstruct Pulmon Dis. 2017;12:2285-2290. doi:10.2147/COPD.S141760

11. Aksoy E, Karakurt Z, Gungor S, et al. Neutrophil to lymphocyte ratio is a better indicator of COPD exacerbation severity in neutrophilic endotypes than eosinophilic endotypes. Int J Chron Obstruct Pulmon Dis. 2018;13:2721-2730. doi:10.2147/COPD

12. Xiong W, Xu M, Zhao Y, Wu X, Pudasaini B, Liu JM. Can we predict the prognosis of COPD with a routine blood test? Int J Chron Obstruct Pulmon Dis. 2017;12:615-625. doi:10.2147/COPD.S124041

13. Bestall JC, Paul EA, Garrod R, Garnham R, Jones PW, Wedzicha JA. Usefulness of the Medical Research Council (MRC) dyspnoea scale as a measure of disability in patients with chronic obstructive pulmonary disease. Thorax. 1999;54 (7):581-586. doi:10.1136/thx.54.7.581 
14. Soler-Cataluña JJ, Martínez-García MA, Sánchez L, Perpiña M, Román P. Severe exacerbations and BODE index: two independent risk factors for death in male COPD patients. Respir Med. 2009;103:692-699. doi:10.1016/j.rmed.2008.12.005

15. Jones PW, Harding G, Berry P, Wiklund I, Chen WH, Kline Leidy N. Development and first validation of the COPD assessment test. Eur Respir J. 2009;34(3):648-654. doi:10.1183/09031936.00102509

16. Miravitlles M, Soler-Cataluña JJ, Calle M, et al. Spanish guidelines for management of chronic obstructive pulmonary disease (GesEPOC) 2017. Pharmacological treatment of stable Phase. Arch Bronconeumol. 2017;53(6):324-335. doi:10.1016/j.arbr.2017.03.017

17. Plaza V, Álvarez F, Calle M, et al. Consensus on the Asthma-COPD Overlap Syndrome (ACOS) between the Spanish COPD guidelines (GesEPOC) and the Spanish Guidelines on the Management of Asthma (GEMA). Arch Bronconeumol. 2017;53(8):443-449. doi:10.1016/j.arbres.2017.04.002

18. Singh D, Agusti A, Anzueto A, et al. Global strategy for the diagnosis, management, and prevention of chronic obstructive lung disease: the GOLD science committee report 2019. Eur Respir J. 2019;53(5):1900164. doi:10.1183/13993003.00164-2019

19. Soler-Cataluña JJ, Martínez-García MA, Román Sánchez $P$, Salcedo E, Navarro M, Ochando R. Severe acute exacerbations and mortality in patients with chronic obstructive pulmonary disease. Thorax. 2005;60(11):925-931. doi:10.1136/thx.2005.040527

20. Doll H, Miravitlles M. Quality of life in acute exacerbations of chronic bronchitis and chronic obstructive pulmonary disease: a review of the literature. Pharmacoeconomics. 2005;23:345-363. doi:10.2165/00019053-200523040-00005

21. Hurst JR, Vestbo J, Anzueto A, et al. Evaluation of COPD Longitudinally to Identify Predictive Surrogate Endpoints (ECLIPSE) Investigators. Susceptibility to exacerbation in chronic obstructive pulmonary disease. N Engl J Med. 2010;63:1128-1138. doi:10.1056/ NEJMoa0909883

22. Yohannes AM, Ershler WB. Anemia in COPD: a systematic review of the prevalence, quality of life, and mortality. Respir Care. 2011;56:644-652. doi:10.4187/respcare.01002

23. Chambellan A, Chailleux E, Similowski T. Prognostic value of the hematocrit in patients with severe COPD receiving long-term oxygen therapy. Chest. 2005;128:1201-1208. doi:10.1378/ chest.128.3.1201

24. Martinez-Rivera C, Portillo K, Muñoz-Ferrer A, et al. Anemia is a mortality predictor in hospitalized patients for COPD exacerbation COPD. 2012;9(3):243-250. doi:10.3109/15412555.2011.647131

25. Toft-Petersen AP, Torp-Pedersen C, Weinreich UM, Rasmussen BS. Association between hemoglobin and prognosis in patients admitted to hospital for COPD. Int $J$ Chron Obstruct Pulmon Dis. 2016;11:2813-2820. doi:10.2147/COPD

26. Park SC, Kim YS, Kang YA, et al. Hemoglobin and mortality in patients with COPD: a nationwide population-based cohort study. Int J Chron Obstruct Pulmon Dis. 2018;13:1599-1605. doi:10.2147/COPD

27. Pepys MB, Hirschfield GM. C-reactive protein: a critical update. $J$ Clin Invest. 2003;111(12):1805-1812. doi:10.1172/JCI200318921

28. Jing Z, Chun C, Ning S, Hong Z, Bei H, Wan-Zhen Y. Systemic inflammatory Marker CRP was better predictor of readmission for AECOPD than sputum inflammatory Markers. Arch Bronconeumol. 2016;52(3):138-144. doi:10.1016/j.arbres.2015.01.011

29. García-Rivero JL, Esquinas C, Barrecheguren M, et al. Risk factors of poor outcomes after admission for a COPD exacerbation: multivariate logistic predictive models. COPD. 2017;14(2):164-169. doi: $10.1080 / 15412555.2016 .1260538$
30. Leuzzi G, Galeone C, Taverna F, Suatoni P, Morelli D, Pastorino U. C-reactive protein level predicts mortality in COPD: a systematic review and meta-analysis. Eur Respir Rev. 2017;26(143):160070. doi:10.1183/16000617.0070-2016

31. Thomsen M, Ingebrigtsen TS, Marott JL, et al. Inflammatory biomarkers and exacerbations in chronic obstructive pulmonary disease. JAMA. 2013;309:2353-2361. doi:10.1001/jama.2013. 5732

32. Janciauskiene S, DeLuca DS, Barrecheguren M, Welte T, Miravitlles M. Serum levels of Alpha1-antitrypsin and their relationship with COPD in the General Spanish Population. Arch Bronconeumol. 2020;56(2):76-83. doi:10.1016/j.arbres.2019.03.001

33. Ellis $\mathrm{P}$, Turner A. What do alpha-1 antitrypsin levels tell us about chronic inflammation in COPD? Arch Bronconeumol. 2020;56(2):7273. doi:10.1016/j.arbres.2019.06.010

34. Nuñez A, Sarasate M, Loeb E, Esquinas C, Miravitlles M, Barrecheguren M. Practical guide to the identification and diagnosis of asthma-COPD overlap (ACO). COPD. 2019;16:1-7. doi:10.1080/ 15412555.2019.1575802

35. Suzuki M, Makita H, Konno S, et al. Hokkaido COPD cohort study investigators. Asthma-like features and clinical course of chronic obstructive pulmonary disease. An analysis from the Hokkaido COPD Cohort Study. Am J Respir Crit Care Med. 2016;194 (11):1358-1365. doi:10.1164/rccm.201602-0353OC

36. Saha S, Brightling CE. Eosinophilic airway inflammation in COPD. Int J COPD. 2006;1(1):39-47. doi:10.2147/copd.2006.1.issue-1

37. Saltürk C, Karakurt Z, Adiguzel N, et al. Does eosinophilic COPD exacerbation have a better patient outcome than non-eosinophilic in the intensive care unit? Int $J$ COPD. 2015;10:1837-1846. doi:10.2147/COPD.S88058

38. Kaveri SV, Mouthon L, Bayry J. Basophil and nephritis in lupus. $N$ Engl $J$ Med. 2010;363(11):1080-1082. doi:10.1056/NEJM cibr1006936

39. Pascual-González Y, López-Sánchez M, Dorca J, Santos S. Defining the role of neutrophil-to-lymphocyte ratio in COPD: a systematic literature review. Int $J$ Chron Obstruct Pulmon Dis. 2018;13:3651-3662. doi:10.2147/COPD

40. Mekov E, Yanev N, Petkov R, Kostadinov D. Neutrophil to lymphocyte ratio in COPD. Thoracic Med. 2018;X(3):8-15.

41. Fawzy A, Putcha N, Paulin LM, et al. SPIROMICS and COPDGene Investigators. Association of thrombocytosis with COPD morbidity: the SPIROMICS and COPDGene cohorts. Respir Res. 2018;19(1):20. doi:10.1186/s12931-018-0717-z.

42. Harrison MT, Short P, Williamson PA, Singanayagam A, Chalmers JD, Schembri S. Thrombocytosis is associated with increased short and long term mortality after exacerbation of chronic obstructive pulmonary disease: a role for antiplatelet therapy? Thorax. 2014;69(7):609-615. doi:10.1136/thoraxjnl2013-203996

43. Karadeniz G, Aktoğu S, Erer OF, et al. Predictive value of platelet-tolymphocyte ratio in exacerbation of chronic obstructive pulmonary disease. Biomark Med. 2016;10:701-710. doi:10.2217/bmm-20160046

44. Kurtipek E, Bekci TT, Kesli R, Sami SS, Terzi Y. The role of neutrophil-lymphocyte ratio and platelet-lymphocyte ratio in exacerbation of chronic obstructive pulmonary disease. J Pak Med Assoc. 2015;65:1283-1287.

45. Kumar P, Law S, Sriram KB. Evaluation of platelet lymphocyte ratio and 90-day mortality in patients with acute exacerbation of chronic obstructive pulmonary disease. J Thorac Dis. 2017;9(6):1509-1516. doi: $10.21037 /$ jtd 


\section{Publish your work in this journal}

The International Journal of COPD is an international, peer-reviewed journal of therapeutics and pharmacology focusing on concise rapid reporting of clinical studies and reviews in COPD. Special focus is given to the pathophysiological processes underlying the disease, intervention programs, patient focused education, and self management protocols. This journal is indexed on PubMed Central, MedLine and CAS. The manuscript management system is completely online and includes a very quick and fair peer-review system, which is all easy to use. Visit http://www.dovepress.com/testimonials.php to read real quotes from published authors.

Submit your manuscript here: https://www.dovepress.com/international-journal-of-chronic-obstructive-pulmonary-disease-journal 